\title{
Biochemical assessments of thyroid profile, serum 25-hydroxycholecalciferol and cluster of differentiation 5 expression levels among children with autism
}

\author{
This article was published in the following Dove Press journal: \\ Neuropsychiatric Disease and Treatment \\ 14 September 2017 \\ Number of times this article has been viewed
}

\author{
Tarek Desoky' \\ Mohammed H Hassan ${ }^{2}$ \\ Hanan M Fayed ${ }^{3}$ \\ Hala M Sakhr ${ }^{4}$ \\ 'Department of Neuropsychiatry, \\ ${ }^{2}$ Department of Medical Biochemistry \\ and Molecular Biology, ${ }^{3}$ Department \\ of Clinical and Chemical Pathology, \\ ${ }^{4}$ Department of Pediatrics, Qena Faculty \\ of Medicine, Qena University Hospitals, \\ South Valley University, Qena, Egypt
}

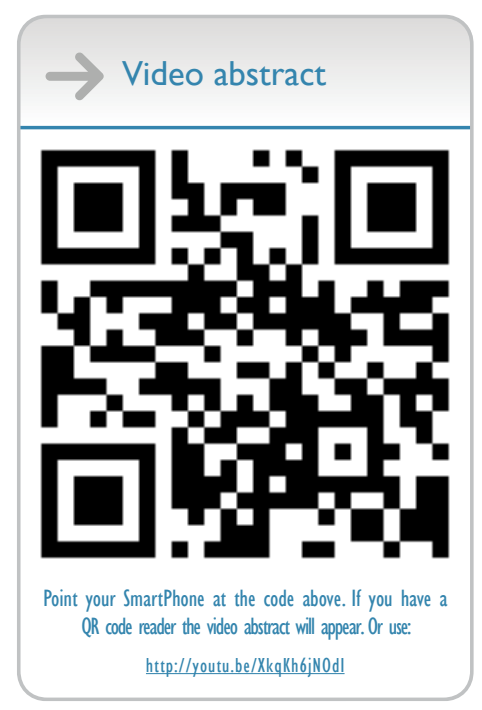

Correspondence: Mohammed H Hassan Department of Medical Biochemistry and Molecular Biology, Qena Faculty of Medicine, South Valley University, Qena, PO Box 83523, Egypt Tel +20 I0 98473605

Email mohammedhosnyhassaan@ yahoo.com
Background: The exact pathogenesis of autism is still unknown. Both thyroid hormones and $25(\mathrm{OH}) \mathrm{D}$ are important for brain development, in addition to CD5; all have immunomodulatory actions by which their dysregulation may have a potential role in autism pathogenesis.

Objectives: The objectives of this study were to assess the thyroid profile, serum 25(OH)D levels and CD5 expression levels among autistic patients and to find out the correlations between the measured biomarkers with each other on one side and with the disease severity on the other side.

Patients and methods: This cross-sectional case-control study has been conducted on 60 children with autism and 40 controls, recruited from Qena Governorate, Upper Egypt. Childhood Autism Rating Scale (CARS) score was used to assess the included patients. Biochemical assays of thyroid function in the form of free triiodothyronine (FT3), free tetraiodothyronine (FT4), thyroid-stimulating hormone (TSH) and $25(\mathrm{OH}) \mathrm{D}$ were done using commercially available enzyme-linked immunosorbent assay (ELISA) kits, while CD5 expression levels were measured using flow cytometry (FCM) analysis for all the included patients and controls.

Results: The overall measurement results show significant higher mean serum TSH levels, mean CD5 expression levels with significant lower mean serum 25(OH)D levels among autistic children when compared with the control group ( $p<0.05$ for all). Significant negative correlations between CD5 with FT3, FT4 and 25(OH)D were observed. CARS score showed significant negative correlations with both FT3 and $25(\mathrm{OH}) \mathrm{D}$, while it was positively correlated with CD5 in a significant manner ( $p<0.05$ for all).

Conclusion: Elevated CD5 expression and decreased 25(OH)D stores could play a potential role in the pathogenesis of autism via their immune-modulator actions. High TSH serum levels among autistic children, although within the physiological range, reflect the presence of thyroid dysfunction among such children, which needs further assessment.

Keywords: thyroid hormones, 25(OH)D, CD5, autism, flow cytometry, ELISA

\section{Introduction}

Autism is a complicated syndrome that affects neurological development characterized by pervasive deficits in the social interaction, verbal and nonverbal communication impairment and stereotyped patterns of interests and activities. ${ }^{1,2}$ The severity of autism can be assessed using Childhood Autism Rating Scale (CARS). ${ }^{3}$

The exact pathogenesis of autism is still unknown; however, genetic, neurologic, environmental and immunological factors may be involved. ${ }^{4}$ 
Vitamin D plays an important role in brain homeostasis and has immunomodulatory, neuroprotective and anti-inflammatory functions. Previous studies reported an association between vitamin D deficiency and neuropsychiatric diseases involving autism. ${ }^{5,6}$ Only $25(\mathrm{OH}) \mathrm{D}$; calcidiol is currently used for the assessment of vitamin D saturation worldwide and reflects the total body stores of vitamin D. ${ }^{7}$ Serum 1,25-(OH)2D3 cannot be used as an indicator for vitamin D3 status as its level may decrease only in severe vitamin D3 deficiency. ${ }^{8}$ Both vitamin D3 and thyroid hormones belong to group-I hormones using steroid hormone receptors. ${ }^{9}$ Thyroid hormones play an essential role in early brain development and significantly affect the whole body activities and functions, and their decrease to a certain degree may cause multiorgan failure. ${ }^{10}$ Vitamin D deficiency may associate with autoimmune thyroid dysfunction. ${ }^{9}$ The CD5 is a transmembrane protein present on the surface of $\mathrm{T}$ cells and on many thymocytes and a subset of B cells surfaces. ${ }^{11}$ High CD5 levels are reported in many autoimmune diseases, providing evidence of CD5 role in the pathogenesis of autoimmunity. ${ }^{12}$

Based on literature, the present novel study aimed to assess and investigate the status and the correlations of $25(\mathrm{OH}) \mathrm{D} 3$, thyroid hormones and CD5 in children with autism, all of which have immunomodulatory actions. Their disturbances may play a role in the occurrence of autoimmunity, supporting the autoimmune theory of autism. In addition, both $25(\mathrm{OH}) \mathrm{D} 3$ and thyroid hormones are important for brain development, and their disturbances may have a role in various neurodevelopmental diseases including autism.

\section{Patients and methods Study design}

This cross-sectional case-control study has been conducted on 60 newly diagnosed autistic children (55 males and five females); their mean age was $7.03 \pm 2.34$ years. They were selected from the outpatients' psychiatric clinics of the Neuropsychiatric and Pediatric Departments of Qena University Hospital(s), South Valley University, Upper Egypt, after approval from the ethics committee of the Qena University. This was in addition to 40 apparently healthy, age-matched volunteers selected as controls (20 males and 20 females). The recruitment of patients and controls in this study was according to the guidelines laid down in the Declaration of Helsinki, and every child's parents were informed about the aim of the study and written consent was given. The total duration of the study was one year, from May 1, 2016 to April 30, 2017.

\section{Patients' evaluation}

All included patients were subjected to detailed history and thorough neuropsychiatric examination. Individual interviews with every included child and his/her parents for clinical assessment of autistic symptoms severity using CARS was conducted. CARS assessed behavior guided by 14 parameters by which autism affected them in addition to one parameter of general autism impression. A score from 1 to 4 for each parameter was assigned as follows: $1=$ no signs of autism (normal behavior for age) and $4=$ severe symptoms of autism (severe affection of behavior). The CARS maximum score of 60 was divided as follows: no autism (15-29.5), mild to moderate autism (30.5-37) and severe autism $(37.5-60))^{3,13}$

\section{Laboratory workup}

A total of $10 \mathrm{~mL}$ of peripheral blood venous samples were drawn from an antecubital vein, which were divided into two vacutainer tubes. A total of $2 \mathrm{~mL}$ was collected on an EDTA tube for flow cytometry (FCM) analysis of the CD5 expression levels using FACSCalibur FCM (BD Biosciences, San Jose, CA, USA). The remaining $8 \mathrm{~mL}$ of venous blood was evacuated into serum separator gel tubes, where the samples were allowed to clot for 30 minutes at $37^{\circ} \mathrm{C}$ before centrifugation for 15 minutes at 3,000 rpm. Separated sera were aliquoted into $1 \mathrm{~mL}$ cryotubes and stored at $-20^{\circ} \mathrm{C}$ till the time of biochemical analysis. All samples were measured in a single assay to avoid repeated freeze-thaw cycles. Commercially available sandwich enzyme-linked immunosorbent assay (ELISA) kits were used for thyroid-stimulating hormone (TSH) and 25(OH)D biochemical analyses, and solid-phase competitive ELISA assay kits were used for assay of free triiodothyronine (FT3) and free tetraiodothyronine (FT4) using ELISA Multiskan EX Microplate Photometer (Stat Fax 2100; Thermo Scientific, Palm city, FL, USA). FT3, FT4 and TSH ELISA assay kits were supplied by Calbiotech Inc. (Spring Valley, CA, USA). The catalog numbers were F3106T for FT3, F4107T for FT4 and TS227T for TSH, while that for 25(OH)D was supplied by Chongqing Biospes Co., Ltd (Chongqing, People's Republic of China). with the catalog number: BYEK1472. Reference values according to the used ELISA kits for the assessment of thyroid profile were $0.7-6.4 \mu \mathrm{IU} / \mathrm{mL}$ for TSH, $1.2-4.4 \mathrm{pg} / \mathrm{mL}$ for FT3 and $0.8-2 \mathrm{ng} / \mathrm{dL}$ for FT4, while for 25(OH)D reference values, ${ }^{14}$ deficiency was considered if its serum level was $<20 \mathrm{ng} / \mathrm{mL}$, insufficiency was considered if its serum level was $>20$ and $<30 \mathrm{ng} / \mathrm{mL}$ and sufficiency was considered if its serum level was $>30 \mathrm{ng} / \mathrm{mL}$. 

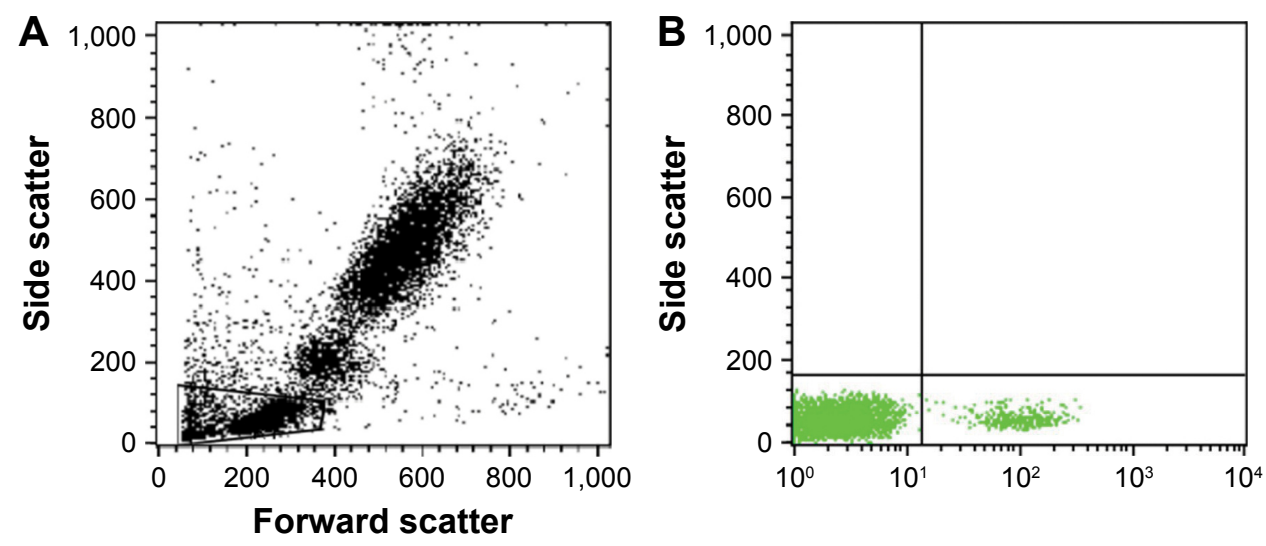

Figure I Flow cytometer dot plot analysis of CD5 expression level subsets.

Notes: (A) Forward scatter and side scatter of peripheral blood, RI (gated lymphocytes). (B) CD5 $5^{+}$lymphocytic expression.

\section{FCM analysis of CD5 expression}

CD5 surface marker expression levels were measured using polyclonal anti-CD5 antibody conjugated to fluorescein isothiocyanate (FITC; Chongqing Biospes Co., Ltd, catalog number: YPA1579). Briefly, as manufacturer's instructions, $100 \mu \mathrm{L}$ of whole blood was stained with $10 \mu \mathrm{L}$ of FITCconjugated, lineage-specific anti-CD5 marker. After 15 min of incubation with the antibodies at room temperature in the dark, RBCs were lyzed using FACS lysing solution and washed with phosphate-buffered saline (PBS). After proper setting, calibration and compensation, an isotype-matched control was used with each sample. The labeled lymphocytes were acquired via the properties of a forward scatter and side scatter dot plot histogram, which was used to define the lymphocyte population (R1) on FCM (Figure 1), and analysis was done using FACSCalibur FCM with CellQuest software version 5.2 (BD Biosciences).

\section{Statistical analysis}

The normality of data and homogeneity variances prior to further statistical analysis were tested using the Anderson-Darling test. Categorical variables were described by number and percent (n, \%), whereas continuous variables were described by mean and standard error of mean (mean, SEM) or mean and standard deviation (mean, SD). Chi-square test and Fisher's exact test were used to compare categorical variables, while Student's $t$-test and analysis of variance (ANOVA) were used to compare continuous quantitative variables of parametric data. Spearman's rank correlation coefficient was used to explore the relationship between quantitative variables. A two-tailed test was considered significant when $p$ was $<0.05$. All analyses were performed using the IBM SPSS version 20.0 software (IBM Corporation, Armonk, NY, USA).

\section{Results}

The demographic and clinical data of the studied patients regarding age, sex, CARS degree and score are presented in Table 1 with significant male predominance in autistic children. The mean serum levels of the studied biomarkers (FT3, FT4, TSH, 25(OH)D and CD5) in children with autism are presented in Table 2 and Figure 2, which revealed significantly lower serum levels of TSH and 25(OH)D and significantly higher expression levels of CD5 in children with

Table I Demographic data of the studied groups

\begin{tabular}{|c|c|c|c|c|c|}
\hline \multirow[t]{2}{*}{ Variables } & \multicolumn{3}{|c|}{ Patients group } & \multirow{2}{*}{$\begin{array}{l}\text { Control } \\
\text { group } \\
(n=40)\end{array}$} & \multirow[t]{2}{*}{$p$-value } \\
\hline & $\begin{array}{l}\text { Patients } \\
\text { (total), } \\
(\mathbf{N}=60)\end{array}$ & $\begin{array}{l}\text { Patients with } \\
\text { mild to moderate } \\
\text { autism }(n=30)\end{array}$ & $\begin{array}{l}\text { Patients with } \\
\text { severe autism } \\
(n=30)\end{array}$ & & \\
\hline Age, mean $\pm S D$ & $7.03 \pm 2.34$ & $6.8 \pm 2.08$ & $7.27 \pm 2.6$ & $7.91 \pm 3.21$ & 0.236 \\
\hline \multicolumn{6}{|l|}{ Sex, n (\%) } \\
\hline Males & $55(92.6)$ & $28(93.3)$ & $27(90.0)$ & $20(50.0)$ & $<0.00 I^{*}$ \\
\hline Females & $5(8.3)$ & $2(6.7)$ & $3(10.0)$ & $20(50.0)$ & \\
\hline CARS score, mean \pm SD & - & $32.67 \pm 1.99$ & $46.8 \pm 4.23$ & - & $<0.001 *$ \\
\hline
\end{tabular}

Note: *Statistically significant difference $(p<0.05)$.

Abbreviations: SD, standard deviation; CARS, Childhood Autism Rating Scale. 
Table 2 Mean \pm SEM of the serum levels of FT3, FT4, TSH, $25(\mathrm{OH}) \mathrm{D}$ and $\mathrm{CD} 5$ in children with autism compared with the control group

\begin{tabular}{llll}
\hline Variables & Patients & Control & p-value \\
\hline FT3 $(\mathrm{pg} / \mathrm{dL})$ & $3.53 \pm 0.54$ & $3.46 \pm 0.36$ & 0.064 \\
FT4 $(\mathrm{ng} / \mathrm{dL})$ & $1.45 \pm 0.13$ & $1.38 \pm 0.09$ & 0.580 \\
TSH $(\mu \mathrm{lU} / \mathrm{mL})$ & $2.25 \pm 1.05$ & $1.45 \pm 0.96$ & $<0.05^{*}$ \\
$25(\mathrm{OH}) \mathrm{D}(\mathrm{ng} / \mathrm{mL})$ & $18.63 \pm 10.8$ & $45.9 \pm 8.85$ & $<0.00 \mathrm{I}^{*}$ \\
$\mathrm{CD} 5(\%)$ & $7 \pm \mathrm{I} .55$ & $2.85 \pm 0.95$ & $<0.0 \mathrm{I}^{*}$ \\
\hline
\end{tabular}

Note: *Statistically significant difference $(p<0.05)$.

Abbreviations: SEM, standard error of mean; FT3, free triiodothyronine; FT4, free tetraiodothyronine; TSH, thyroid-stimulating hormone.

autism when compared with the control group. In addition, the altered levels of such biomarkers were more marked in children with severe autism when compared with those having mild to moderate autism as presented in Table 3. Classification of the included children with autism according to the status of $25(\mathrm{OH}) \mathrm{D}$ is presented in Table 4, where deficient status was more obvious in children with severe degree than those with mild to moderate degree. The correlations of the studied biomarkers among children with autism are presented in Table 5, which reveal significant negative correlations of CD5 with FT3, FT4 and 25(OH)D. The correlations of the studied biomarkers among autistic children with CARS score are presented in Table 6, which reveal significant negative correlations of CARS score with both FT3 and 25(OH)D, while it is positively correlated with CD5 in a statistically significant manner.

\section{Discussion}

Autism spectrum disorder (ASD) is a severe disorder that affects the neurological development, characterized by disturbances in the social interaction and communication, in addition to stereotyped repetitive behaviors. Its prevalence differs by the region, but a higher prevalence of up to 1:88 child has been reported. ${ }^{15}$ Because the etiology of autism is a highly contemporary field of research in neuroscience and psychiatry and can be considered as a challenging issue as there is no direct mechanism that can simply explain the pathogenesis of autism, the present study investigated a group of biomarkers with different degrees of autism severity and searched the possible resulting correlations that may provide new insights on autism diagnosis and therapy.

There is increasing knowledge that normal thyroid function is required for normal neurological development and thyroid dysfunction associated with many neurodevelopmental disorders including ASD. ${ }^{16,17}$ The findings of the present study revealed significantly higher TSH serum levels with nonsignificant differences in the serum levels of FT3 and FT4 among children with autism when compared with the controls with significantly higher serum levels among children with severe degree of autism versus those having mild to moderate autism, suggesting the presence of subclinical hypothyroidism in autistic children, although the serum levels of TSH still fall within the normal range, which is wide. In addition, there was a significant negative correlation between FT3 and CARS score. These findings were in agreement with the study of Khan, ${ }^{18}$ who reported a high rate of hypothyroidism in children with autism. Nir et a ${ }^{19}$ reported larger diurnal variation in TSH serum levels in comparison with controls explaining the possible thyroid dysfunction in ASD in relation to hypothalamic-pituitary axis. Although the
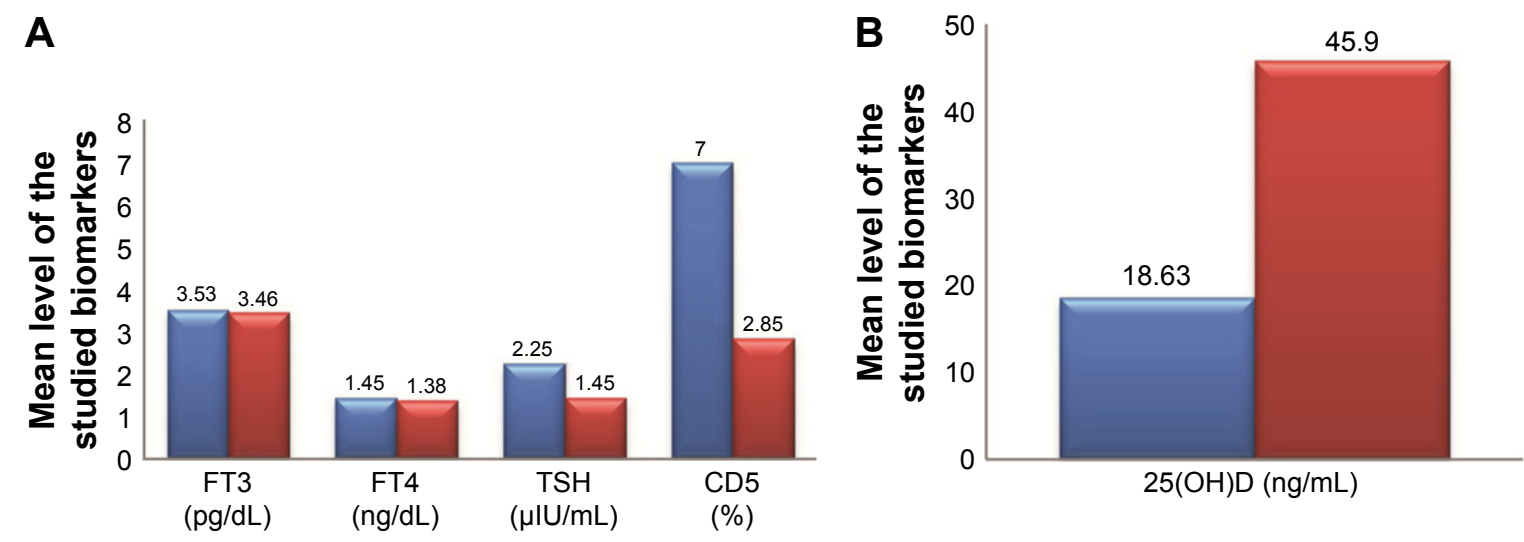

$\square$ Patients with autism Control group

Figure 2 Comparisons between the mean levels of FT3, FT4, TSH, CD5 (A) and 25(OH)D (B) in patients with autism versus the control group. Abbreviations: FT3, free triiodothyronine; FT4, free tetraiodothyronine; TSH, thyroid-stimulating hormone. 
Table 3 Mean \pm SEM of the serum levels of FT3, FT4, TSH, 25(OH)D and CD5 among children with autism according to CARS degree versus the control group

\begin{tabular}{|c|c|c|c|c|}
\hline Variables & $\begin{array}{l}\text { Children with } \\
\text { mild to moderate } \\
\text { degree of autism }\end{array}$ & $\begin{array}{l}\text { Children with } \\
\text { severe degree } \\
\text { of autism }\end{array}$ & $\begin{array}{l}\text { Control } \\
\text { group } \\
(n=40)\end{array}$ & $p$-value \\
\hline FT3 (pg/dL) & $3.67 \pm 0.53$ & $3.39 \pm 0.52$ & $3.46 \pm 0.36$ & 0.060 \\
\hline FT4 (ng/dL) & $1.47 \pm 0.13$ & $1.42 \pm 0.12$ & $1.38 \pm 0.09$ & 0.080 \\
\hline $\mathrm{TSH}(\mu \mathrm{IU} / \mathrm{mL})$ & $2.11 \pm 1.03$ & $2.38 \pm 1.08$ & $1.45 \pm 0.96$ & $<0.05^{*}$ \\
\hline 25(OH)D3 (ng/mL) & $24.08 \pm 10.62$ & $13.19 \pm 7.94$ & $45.9 \pm 8.85$ & $<0.00 I^{*}$ \\
\hline CD5 (\%) & $5.8 \pm 0.76$ & $8.2 \pm 1.16$ & $2.85 \pm 0.95$ & $<0.001 *$ \\
\hline
\end{tabular}

Note: *Statistically significant difference $(p<0.05)$.

Abbreviations: SEM, standard error of mean; FT3, free triiodothyronine; FT4, free tetraiodothyronine; TSH, thyroid-stimulating hormone; CARS, Childhood Autism Rating Scale.

exact mechanism between thyroid dysfunction and neuropsychiatric disorders is unclear, Frye et a ${ }^{20}$ concluded that the presence of folate receptor $\alpha$-autoantibodies (in up to $70 \%$ of autistic patients) contributes to the higher TSH levels and hence the occurrence of thyroid dysfunction in children with autism. Folate is not a prominent cofactor in the synthesis of thyroid hormones, but it is an essential cofactor for phenylalanine hydroxylase in the form of tetrahydrobiopterin (derived from folate cycle) required for conversion of phenylalanine into tyrosine amino acid from which thyroid hormones are synthesized. ${ }^{21}$ Hoshiko et al ${ }^{16}$ reported an association between low thyroid hormones at birth and the occurrence of subsequently diagnosed ASD, stating that compensatory mechanism for production of lower thyroid hormones may allow their return to normal or near-normal levels with persistent neurodevelopmental impairment even after the thyroid hormone levels themselves have returned to normal. In contrast, some studies failed to confirm the occurrence of thyroid dysfunction and reported no differences in TSH, T3 and T4 in patients with autism versus the controls..$^{22,23}$

The findings of the present study revealed significant lower serum levels of 25(OH)D among autistic children,

Table 4 Classification of the included children with autism according to the status of $25(\mathrm{OH}) \mathrm{D}$

\begin{tabular}{llll}
\hline 25(OH)D status & $\begin{array}{l}\text { Children } \\
\text { with mild to } \\
\text { moderate } \\
\text { autism }(\mathbf{n}=\mathbf{3 0})\end{array}$ & $\begin{array}{l}\text { Children } \\
\text { with severe } \\
\text { autism } \\
(\mathbf{n}=\mathbf{3 0})\end{array}$ & p-value \\
\hline $\begin{array}{l}\text { Sufficient }(>30 \mathrm{ng} / \mathrm{mL}), \\
\mathrm{n}(\%)\end{array}$ & $6(13.6)$ & $4(9.1)$ & $<0.05^{*}$ \\
$\begin{array}{l}\text { Insufficient }(20-30 \mathrm{ng} / \mathrm{mL}), \\
\mathrm{n}(\%)\end{array}$ & $6(13.6)$ & $0(0.0)$ & \\
$\begin{array}{l}\text { Deficient }(<20 \mathrm{ng} / \mathrm{mL}), \\
\mathrm{n}(\%)\end{array}$ & $18(40.9)$ & $26(59.1)$ & \\
\hline
\end{tabular}

Note: *Statistically significant difference $(p<0.05)$. especially those having severe degree when compared with the control group with higher frequency of $25(\mathrm{OH}) \mathrm{D}$ deficiency in severe autism than mild to moderate autism in which higher frequency of 25(OH)D insufficiency was noticed. In addition, there was significant negative correlation between 25(OH)D and CARS score reflecting an inverse association with disease severity. These findings were in agreement with several studies, ${ }^{24-26}$ explaining that the immunoregulatory function of $25(\mathrm{OH}) \mathrm{D}$ has been lost by the presence of lower vitamin D stores, contributing to the occurrence and severity of autism through the raised autoimmunity, and this was confirmed in one of the previously mentioned studies by the improvement in autism symptoms following vitamin D supplementation to such patients. ${ }^{24}$ Although MacKawy et al, ${ }^{9}$ reported that serum levels of $25(\mathrm{OH}) \mathrm{D}$ was positively correlated with $\mathrm{T} 3$, while, negatively correlated with TSH among hypothyroid patients, in a statistically significant manner, the present study didn't show any significant correlations between serum levels of $25(\mathrm{OH})$ D with FT3, FT4 or TSH, which could be explained by the mild degree of thyroid dysfunction noticed among the included autistic children.

Table 5 Correlations of the serum levels of FT3, FT4, TSH, 25(OH)D and CD5 among children with autism

\begin{tabular}{|c|c|c|c|c|c|}
\hline \multirow{2}{*}{$\begin{array}{l}\text { Variables } \\
25(\mathrm{OH}) \mathrm{D}\end{array}$} & \multicolumn{2}{|c|}{ FT3 (pg/dL) } & \multirow{2}{*}{$\begin{array}{l}\begin{array}{l}\text { FT4 } \\
\text { (ng/dL) }\end{array} \\
-0.200\end{array}$} & \multirow{2}{*}{$\begin{array}{l}\begin{array}{l}\text { TSH } \\
(\mu \mid \mathrm{U} / \mathrm{mL})\end{array} \\
0.109\end{array}$} & \multirow{2}{*}{$\begin{array}{l}\text { 25(OH)D } \\
\text { (ng/mL) }\end{array}$} \\
\hline & $r$ & -0.080 & & & \\
\hline$(\mathrm{ng} / \mathrm{mL})$ & $p$-value & 0.544 & 0.126 & 0.407 & \\
\hline \multirow[t]{2}{*}{ CD5 (\%) } & $r$ & -0.371 & -0.297 & 0.130 & -0.01 \\
\hline & $p$-value & $<0.0 I^{*}$ & $<0.05^{*}$ & 0.322 & $<0.05^{*}$ \\
\hline
\end{tabular}

Note: *Statistically significant difference $(p<0.05)$.

Abbreviations: FT3, free triiodothyronine; FT4, free tetraiodothyronine; TSH, thyroid-stimulating hormone. 
Table 6 Correlations of the serum levels of FT3, FT4, TSH, 25(OH)D and CD5 among autistic children with CARS score

\begin{tabular}{lll}
\hline Variables & \multicolumn{2}{l}{ CARS score } \\
\cline { 2 - 3 } & $\boldsymbol{r}$ & $\boldsymbol{p}$-value \\
\hline FT3 $(\mathrm{pg} / \mathrm{dL})$ & -0.329 & $<0.05^{*}$ \\
$\mathrm{FT} 4(\mathrm{ng} / \mathrm{dL})$ & -0.195 & 0.135 \\
$\mathrm{TSH}(\mu \mathrm{lU} / \mathrm{mL})$ & 0.183 & 0.162 \\
$25(\mathrm{OH}) \mathrm{D}(\mathrm{ng} / \mathrm{mL})$ & -0.582 & $<0.00 I^{*}$ \\
$\mathrm{CD} 5(\%)$ & 0.808 & $<0.00 I^{*}$ \\
\hline
\end{tabular}

Note: *Statistically significant difference $(p<0.05)$.

Abbreviations: FT3, free triiodothyronine; FT4, free tetraiodothyronine; TSH, thyroid-stimulating hormone; CARS, Childhood Autism Rating Scale.

Our study showed significantly higher expression levels of CD5 among autistic patients, especially those with severe degree, in comparison with those in the control group with significant positive correlation with CARS score and hence severe degree of autism. Only one study could be traced in the literature investigating CD5 plasma levels and their associations with CARS score in autism, which was in agreement with our findings, strengthening the immune dysregulation hypothesis and the raised autoimmunity in autism pathogenesis. ${ }^{27}$ Our study differs from theirs in the method of CD5 assay, in which Halepoto et a ${ }^{27}$ used ELISA in the assessment of CD5 expression levels, while we used FCM. Explanation for such findings needs further molecular research.

To the best of our knowledge, the present study is the first original research investigating the correlations between thyroid hormones, 25(OH)D and CD5 in autism, and we report the following correlations that may be promising in understanding the pathophysiology of autism. There were significant negative correlations of CD5 with FT3, FT4 and 25(OH)D, which indicate that the higher the CD5, the lower the FT3, FT4 and 25(OH) $\mathrm{D}$ and the higher the CARS score and hence the increased degree of autism severity. These findings may open new roads regarding the therapeutic approach in autism and future studies regarding the combined use of vitamin D supplementations with immunomodulatory drugs specifically act on CD5 should be researched as a new guideline in autism therapy.

\section{Conclusion}

The findings of the present study support the autoimmunity theory in autism pathogenesis as all the studied biomarkers (thyroid hormones, 25(OH)D and CD5) have direct or indirect immunoregulatory role in the human body and are disturbed in autistic patients.

\section{Study limitations}

The relatively small study sample and the cross sectional nature of the study.

\section{Disclosure}

The authors report no conflicts of interest in this work.

\section{References}

1. Bjørklund G, Saad K, Chirumbolo S, et al. Immune dysfunction and neuroinflammation in autism spectrum disorder. Acta Neurobiol Exp (Wars). 2016;76(4):257-268.

2. Wang T, DU L, Shan L, Jia FY. Research advances in immunological dysfunction in children with autism spectrum disorders. Zhongguo Dang Dai Er Ke Za Zhi. 2014;16(12):1289-1293.

3. Rellini E, Tortolani D, Trillo S, Carbone S, Montecchi F. Childhood Autism Rating Scale (CARS) and Autism Behavior Checklist (ABC) correspondence and conflicts with DSM-IV criteria in diagnosis of autism. J Autism Dev Disord. 2004;34(6):703-708.

4. Elamin NE, Al-Ayadhi LY. Brain autoantibodies in autism spectrum disorder. Biomarks Med. 2014;8:345-352.

5. Cannell JJ, Grant WB. What is the role of vitamin D in autism? Dermatoendocrinology. 2013;5(1):199-204.

6. Endres D, Dersch R, Stich O, et al. Vitamin D deficiency in adult patients with schizophreniform and autism spectrum syndromes: a one-year cohort study at a German Tertiary Care Hospital. Front Psychiatry. 2016;7:168.

7. Vondra K, Stárka L, Hampl R. Vitamin D and thyroid diseases. Physiol Res. 2015;64(2):95-100.

8. Dawson-Hughes B, Heaney RP, Holick MF, Lips P, Meunier PJ, Vieth R. Estimates of optimal vitamin D status. Osteoporos Int. 2005; 16(7):713-716

9. Mackawy AMH, Al-ayed BM, Al-rashidi BM. Vitamin D deficiency and its association with thyroid disease. Int J Health Sci. 2013;7(3): 267-275.

10. Saranac L, Zivanovic S, Bjelakovic B, Stamenkovic H, Novak M, Kamenov B. Why is the thyroid so prone to autoimmune disease. Horm Res Paediatr. 2011;75(3):157-165.

11. Kipps TJ. The CD5 B cell. Adv Immunol. 1989;47:117-185.

12. Sigal LH. Basic science for the clinician 54: CD5. J Clin Rheumatol. 2012;18(2):83-88.

13. Geier DA, Kern JK, Geier MR. A Comparison of the Autism Treatment Evaluation Checklist (ATEC) and the Childhood Autism Rating Scale (CARS) for the quantitative evaluation of autism. J Ment Health Res Intellect Disabil. 2013;6(4):255-267.

14. Holick MF. Vitamin D deficiency. N Engl J Med. 2007;357:266-281.

15. Angelidou A, Asadi S, Alysandratos K, Karagkouni A, Kourembanas S, Theoharides TC. Perinatal stress, brain inflammation and risk of autismreview and proposal. BMC Pediatr. 2012;12(1):89.

16. Hoshiko S, Grether JK, Windham GC, Smith D, Fessel K. Are thyroid hormone concentrations at birth associated with subsequent autism diagnosis? Autism Res. 2011;4(6):456-463.

17. Rovet JF. The role of thyroid hormones for brain development and cognitive function. Endocr Dev. 2014;26:26-43.

18. Khan AA. Thyroid dysfunction. Br Med J. 1970;4:495.

19. Nir I, Meir D, Zilber N, Knobler H, Hadjez J, Lerner Y. Brief report: circadian melatonin, thyroid-stimulating hormone, prolactin, and cortisol levels in serum of young adults with autism. J Autism Dev Disord. 1995;25(6):641-654.

20. Frye RE, Wynne R, Rose $S$, et al. Thyroid dysfunction in children with autism spectrum disorder is associated with folate receptor $\alpha$ autoimmune disorder. J Neuroendocrinol. 2017;29(3):1-12.

21. Frye RE, De Latorre R, Taylor HB, et al. Metabolic effects of sapropterin treatment in autism spectrum disorder: a preliminary study. Transl Psychiatry. 2013;3(3):1-9.

22. Abbassi V, Linscheid T, Coleman M. Triiodothyronine (T3) concentration and therapy in autistic children. J Autism Child Schizophr. 1978;8(4):383-387.

23. Cohen DJ, Young JG, Lowe TL, Harcherik D. Thyroid hormone in autistic children. J Autism Dev Disord. 1980;10(4):445-450.

24. Saad K, Abdel-Rahman AA, Elserogy YM, et al. Vitamin D status in autism spectrum disorders and the efficacy of vitamin D supplementation in autistic children. Nutr Neurosci. 2016;19(8):346-351. 
25. Mostafa GA, Al-Ayadhi LY. Reduced serum concentrations of 25-hydroxy vitamin D in children with autism: relation to autoimmunity. J Neuroinflammation. 2012;9:1-7.

26. Meguid NA, Hashish AF, Amwar M, Sidhom G. Reduced serum levels of 25-hydroxy and 1,25-dihydroxy vitamin D in Egyptian children with autism. J Altern Complement Med. 2010;16(6):641-645.
27. Halepoto DM, Alhowikan AM, Ayadhi LA. Cluster of differentiation 5 (CD5) levels in the plasma of children with autism spectrum disorder (ASD). J Coll Physicians Surg Pak. 2017;27(3):149-152.

\section{Publish your work in this journal}

Neuropsychiatric Disease and Treatment is an international, peerreviewed journal of clinical therapeutics and pharmacology focusing on concise rapid reporting of clinical or pre-clinical studies on a range of neuropsychiatric and neurological disorders. This journal is indexed on PubMed Central, the 'PsycINFO' database and CAS, and is the official journal of The International Neuropsychiatric Association (INA). The manuscript management system is completely online and includes a very quick and fair peer-review system, which is all easy to use. Visit http://www.dovepress.com/testimonials.php to read real quotes from published authors.

Submit your manuscript here: http://www.dovepress.com/neuropsychiatric-disease-and-treatment-journal 